\title{
A REPORT OF TEN CASES OF INFANTILE HYPERTROPIC PYLORIC STENOSIS TREATED BY RAMSTEDT'S OPERATION
}

Narayan Das

1. Assistant Professor. Department of General Surgery, Agartala Government Medical College \& G.B Pant Hospital, Agartala, Tripura West.

\section{CORRESPONDING AUTHOR:}

Dr. Narayan Das MBBS, MS (Gen. Surgery),

Old Kalibari lane, (Near Skylark Club),

Kerchoumohani, Krishnanagar,

Agartala, Tripura (West), 799001.

E-mail: narayandas9862019118@gmail.com

\begin{abstract}
Infantile Hypertrophic Pyloric Stenosis (IHPS) is a most common cause of intestinal obstruction in infancy. This condition is usually diagnosed before the baby is 6 months of life. This report describes the ten infants presented with infantile hypertrophic pyloric stenosis. The treatment involved pyloromyotomy (Ramstedt's operation) with very satisfactory result.
\end{abstract}

KEY WORDS: Infantile hypertrophic pyloric stenosis, Ramstedt's operation.

INTRODUCTION: Infantile hypertrophic pyloric stenosis (IHPS) is a benign and well-known surgical problem within the pediatric population. It occurs in approximately 2 to 4 per 1000 live births. The treatment is quickly successful and very rewarding to both parents and surgeon. This report documents ten infants of Infantile hypertrophic pyloric stenosis managed in the hospital.

CASES REPORT: During a period of one year from 1 $1^{\text {st }}$ January 2011 to $31^{\text {st }}$ December2011, ten infants were referred from the department of Paediatric of Agartala Govt.Medical College \&GBPant Hospital to the department of Surgery of Agartala Govt. Medical College \&G B Pant Hospital, with severe vomiting of milk after feeding. The vomitus was non bloody and nonbilious and projectile in nature. The babies presented in between 23 days to 2 months of life (mean 30.6days). Per abdominal examination were normal. Abdominal Ultrasonography suggestive of Infantile Hypertrophic Pyloric Stenosis. The patients were prepared for surgery after resuscitation, under GA, wih adequate monitoring and vigilance. Ramstedt's operation were performed. The post operative courses were uneventful and patients were discharged in time.

DISCUSSION: Infantile hypertrophic pyloric stenosis(IHPS) is an uncommon condition affecting the opening (pylorus) between the stomach and small intestine in infancy (1). It is a benign condition that cause severe projectile non-bilious vomiting in the first few months of life (2). Infantile hypertrophic pyloric stenosis occurs more often in boys then in a girls, and is rare in children older than 6 months (3). The etiology of this condition is still unclear, but there is a genetic predisposition for the disease (4). Ultrasonography is the preferred diagnostic study. Barium X-ray can be diagnosed by showing the narrowed pyloric outlet filled with a thin stream of contrast material, a "string sign" or the "rail road tract sign". The definitive treatment of Infantile hypertrophic pyloric stenosis with surgical pyloromyotomy known as Ramstedt's 
operation. This is a relatively straight forward surgery that can possibly be done through a single incision (usually 3-4 cm long) or laparoscopically (through several tiny incisions), depending on the surgeon's experience and preference (5). Early post operative feeding is safe and effective frequently allowing discharge on the first postoperative day (6).

CONCLUSION: Infantile hypertrophic pyloric stenosis is a pediatric surgical problem that is easily diagnosed by ultrasonography and it is typically managed with surgery and is very rewarding to both parents and surgeon.

\section{REFERENCES:}

1. Hunter AK, Liacouas CA. Pyloric stenosis and congenital anomalies of the stomach.in: Kleiman RM, Behrman RE, Jenson BF,eds. Nelson Text book of Pediatrics. 19 ${ }^{\text {th }}$ Ed. Philadelphia,Pa: Saunders Elsevier.2007; Chap 321.

2. Hal ka F, camball T J, Harrison MW. Evolution in the recognition of infantile hypertrophic pyloric stenosis. Pediatric. 19997;100:1542.

3. Askew, Nathan. An overview of infantile hypertrophic pyloric stenosis. Paediatric nursing. 2010;22(8):27-30.

4. Dowshen, Steven. Pyloric stenosis. The Nemours Foundation. 2007;11:12-30.

5. Medical News: Laparoscopic Repair of pediatric pyloric stenosis may speed Recovery- in surgery. Thoracic surgery from Medpage Today.2009-01-16. Retrieved 2012-02-21.

6. Kenneth S, Azarow, Robert A. Pediatric surgery. Surg Clin N Am.2012;92:528-39.

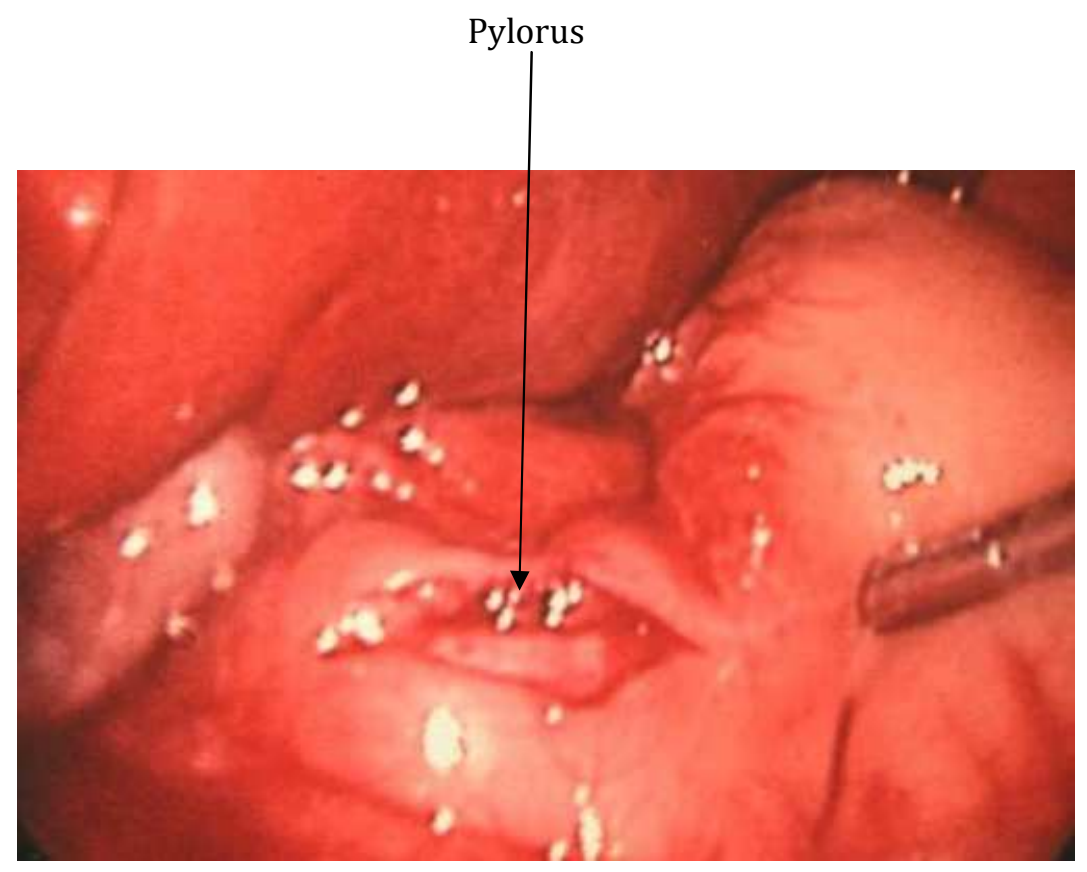

Picture of Ramstedt's operation. 